\title{
RETENTION STRATEGY AND EMPLOYEE'S TURNOVER AMONG ACADEMIC STAFF OF LAGOS STATE OWNED TERTIARY INSTITUTIONS
}

\author{
IDOWU, Oluwatoyin Frederick \\ Department of Industrial Relations and Personnel Management, Lagos State University, Ojo \\ idowoluwatoyin@gmail.com \\ DOI: 10.36108/ljerhrm/8102.01.0142
}

\begin{abstract}
The study investigated the influence of retention strategies of tertiary institutions on academic staff turnover. Employing exploratory study, the Key Informant Interview (KII) combined with Focused Group Discussion (FGD) was deployed to elicit responses from third party respondents in two (2) Lagos State owned tertiary institutions. Descriptive statistics were used to describe the responses obtained. It was found that the same pattern of retention strategic offerings obtained in the two institutions. The distinguishing turnover factor (TF) for the two institutions was the differences in agency (leadership/management) dispositions to academic staff in terms of creating an enabling environment and climate that meet the expectations of academic staff in an ideal academic milieu. The study also established that differential academic status (cadres) require differential retention strategies to reduce the risk of turnover among the cadres. It was recommended among other things that tertiary institutions' management need to periodically examine the existing value propositions profile offered to their academic staff in terms of their sufficiency and adequacy in comparison to what obtain in other global clime if they are not to further lose competent staff to competitors at both local and international academic market space
\end{abstract}

Key Words: Academic Market Space, Leadership, Retention Strategies,Turnover

\section{Introduction}

Employees are essential component parts of business organizations. It is important to hold on to the employees that are key source of organization competence (Hira, 2011) and knowledge. However, organizations globally continue to witness migration of their talents and high performing employees to other organizations, not bearing in mind the strategic implications for business operational effectiveness, competitiveness and goal accomplishment. Attracting and retaining skilled workers is a critical challenge for business organizations' competitiveness.Therefore, organization management crafts strategies to enlist the mind of their workers and engage them in a dependable and competitive manner. Notwithstanding, employees, including academic staff, continue to leave their organization to others in an alarming rate and those leaving cannot be stopped (Samuel \&Chipunza, 2013). Employee Turnover (ET) is simply quitting an organization as a result of factor(s) which could border on justice or injustice, dissatisfaction and inequity in the access to the resources of the organization. Employee turnover is therefore a movement of employees out of the organization. The rate of employee turnover becomes worrisome as high rate can affect productivity and cost of recruiting new employees.

The reasons for employee turnover have also been linked with the ineffectiveness and unsatisfactory nature of enacted policies on implementation of existing retention strategies. Retention and turnover therefore operate in a pull-push fashion. The factors that guarantee retention of workers (pull) also act in pushing them away if the retention factors are not sufficiently met or are denied out rightly. For instance factors like pay, justice, equity, career advancement, supervision and relationship when perceived as sufficient will likely serve to retain employees (pull factors). They will also serve as turnover factors when they are perceived by workers as inadequate (push factor).

Organizations that design and effectively implement strong retention strategies will more likely experience low turnover intention (TI), impact on employee commitment, dedication and customer satisfaction (Das\& Burah, 2013, Gberevbie, 2009). Employee retention strategy is a systematic effort on the part of organization management to create and foster an environment where workers remain and committedly work for the organization. The strategies come with policies and practices on the part of the management..

Organization will continue to rely on its human resource for them to deliver on their business strategies. To do so also mean that skilled, knowledgeable or talent employees must be hired. It is not enough for such employees to be present at work. It is also equally important for such employees to be dedicated, committed, engaged and be satisfied with the work environment. Otherwise, when the policies, practices, processes and programs of the 
organization become dissatisfactory to the employees, the intention to quit becomes high. The essence is not to keep all employees. It is, as Frank, et al(2004) is quoted in Hira (2011) to keep the desirable workers in order to meet business objectives. These are employees that give both the essential and differentiating competencies in the organization. There are many drivers of employees' turnover (ET)like pay, injustice, inequity, career opportunity, supervision and relationship. The influence of each of these turnover drivers in engendering employees' turnover need to be evaluated. The focus of management has been on what they do, to the neglect of the pull away factors of what competitors are doing; leading to depletion of talents, render operational strategies ineffective.

\section{Statement of the Problem}

The number of academic staff available is grossly insufficient to meet the staffing requirement of both the public and private tertiary institutions in many countries including Nigeria (Nge'ethe, Iravo \& Namusonge, 2012). In spite of this shortage in supply, many institutions in Nigeria continue to lose their academic staff to smaller countries like Rwanda, Swaziland, Botswana and Ghana, and to big countries like South Africa, and many developed countries (Nge'ethe et al, 2012). The mass movement can be attributed to the inadequacy and insufficiency of retention strategies put in place by various Nigerian academic institutions when compared to what obtain in the institutions those that migrated moved to. This suggests that turnover rate with its attendant consequences portend negative consequences for tertiary institutions if their retention strategies are not effective. a long time in their employment and reduce turnover among them. Otherwise, organizational objectives may become jeopardized. The cost of searching for alternative employees may be high, expertise may be lost and morale and productivity can become low and the strategic objectives may not be met.

University academics are well trained personnels. The need for a University to retain this category of employees become important as many university- public and private are stemming up geometrically: from five university in 1965 to 12 in1975 to one hundred and forty five as at March, 2016 in Nigeria alone. The mobility amongst academic staff is high and the push - pull effect could be high if effective retention strategies are not put in place to stem the tide. The situation become more challenging as the terrain of academic staff covers the universities in the whole world and perhaps other industries. With the increasing number of universities in Nigeria, Africa and the world at large, the luxury of choice of talented university academic staff becomes widened (Samuel \& Chipunza, 2013). The drivers of retention and turnover had been researched in various industries. Training, career growth and development, pay and welfare are some flash points (Vasquey 2014;Mohanty \& Mohanty, 2014; Samuel\& Chipunza 2013;) What have not been much studied are the likely shortage of academic staff in university and the real factors of their movement to other institutions and other industries have not been critically studied in African countries (Samuel \& Chinpuza, 2013; Ng'ethe, et al, 2012). The rate at which these occur for different cadres of academic staff had not been sufficiently researched also this study intends to fill these gaps.

\section{Research Questions}

Arising from the research problem statement, the following research questions are posed:

1. Do the retention strategies in place influence academic staff retention?

2. Are there differences in the retention strategies that influence the willingness to stay for different categories of academic staff?

\section{Research Objectives}

The objective of the study is to find the relationship between retention strategies and turnover among academic staff Lagos State owned tertiary institutions. This is further broken down as follows:

1) To investigate if retention strategiesput in place by the institutions influence retention.

2) To investigate if factors responsible for remaining with the institutions are different among academic staff cadres.

The study is significant in revealing why academic staff remain or quit the institutions. It will inform the management on how effective its retention strategy on specific areas had been and what remedial actions to take so as not to further lose competent staff. It will remove management focus on what they do to what other institutions are doing that may pull their staff away.

\section{Literature Review}

Staff turnover is an indication that certain things are wrong with the organisation's retention strategies. It could be that the organisation does not keep a tab on its strategies to detect for ineffectiveness and the value workers place on them. 
Yet turnover rate has not been sufficiently documented in developing countries compare to the developed(Ng'ethe et al 2012; Samuel \& Chipunza 2013). In developed countries for instance, it was reported that Australia has academic shortage of 20,000 (Ng'ethe et al, 2012).Of the 7.7\% that left in US $29 \%$ of these were retirees while $71 \%$ left for other reason (Ng'ethe, et al, 2012). This is suggesting that there are more of voluntary exit bordering on pull factors external to the institutions than the involuntary retirement factors. That is the retention factors outside the organization are better than the organization that the organization is leaving. In most cases, academic staff turnover is attributed to brain drain in Africa(Ng'ethe et al 2012; Samuel \& Chipunza 2013).

In Africa Samuel and Chipunza(2012), as cited in Osalusi (2010) hold that Nigeria has lost from 1980s to the $21^{\text {st }}$ Century academic staff to smaller countries like Rwanda, Botswana bigger countries as Britain, America, France and Germany or to other more rewarding jobs. In spite of these, research on academic staff turnover has been sparse. It is necessary to know why academic staff stay in or live their job. This is necessary so as to provide remedial action. Ng'ethe et al (2012) concluded that a clear picture of critical factor influencing academic staff retention has not emerged from previous studies and advised for a longitudinalstudy of academic turnover.

There is a relationship between retention strategy of an organisation and the rate of employee turnover. A meaningful work environment tends to offer satisfaction and motivation (Mantz, 2015) and high retention for workers. Turnover is the number of staff that discontinues working for an organisation within a period of time. Employees leave an organisation for reasons that could be voluntary and involuntary(Chukwu, Ofotokun, Fadeji, \& Sule, 2013). It could also be a reason that is personal or professional as Sandhya \& Kumor (2011) demonstrated. Retention strategies of an organisation can go a long way to pressurise turnover rate or stem it (Sandhya \& Kumor, 2011; Chukwu, et al, 2013; Gberevbie, 2009, 2010; Ng'ethe, et al 2012).

Employee retention according to Hira (2011) could be termed as the effort put in place by employers to keep knowledge, talent and desirable workers in order to meet strategically the strategic business objectives of the organisation. It is an important measure of an organisation health, survival and success (Borstoff \& Marker 2007; Akindele, Oginni \& Omoyele 2012; Oginni, Ogunlusi, \& Faseyiku, 2013).

Attracting and retaining academic staff and minimizing their attrition are critical to academic sector. Tertiary institutions have the most specialised and skilled intellectual. They are set up to meet and nurture the manpower needs of the society. Ng'ethe et a,l (2012) and Nwadiani, (2012) noted that academics staff is central to the function and effectiveness of university educational function and useful to the wider society confirmed. Effective retention strategies of the academic staff and reducing turnover are important because of the pull factors in the academic environment. Academic staff is a global talent and therefore has the luxury of choice to move to any other tertiary institutions (Samuel \& Chipunza, 2013; Ng'ethe et al 2012; Ajadi, 2010; Akindele et al, 2012; and Oginni et al, 2013).

Academic staff are short in supply and the number required to satisfy the emerging tertiary institution in both the public and private ones are not yet known.(Akindele et al 2012, Oginni, et al, 2013; Ajadi et al 2010). Ajadi ,2010) alluded to the fact that the quality and quantity of academic staff available in Nigeria are too short of the need of the public universities not to talk of private universities that have the challenge of regular academic staff but rely on large number of associate or sabbatical staff from public universities. Retention management therefore becomes imperative for tertiary institutions management so as not to lose their staff to other institutions

Samuel \& Chipunza (2013) reported the high competitiveness among South African Universities and research landscape for recruitment of top academics. Accreditation of Universities by National University Commission (NUC) demands that universities keep in their stable academic staff in right quality and quantity and in proportion to the student population. Samuel and Chipunza (2013) noted that research outputs and academic excellence are factors of global ranking of universities

With the shortage of academic staff, as revealed by studies, it is necessary to make the academic environment meaningful enough for all categories of academic staff to choose to remain and contribute committedly and dependably to the strategic objectives of the institution.

\section{Retention strategies and Academic staff turnover}

There are varied reasons why academic staff quit. Factor of leadership, culture, and competition are reported by Bhatt (2015), Akindele, et al (2012), Vasquey (2014), Samuel\& Chipunza (2013). Opportunities for growth and development including promotion opportunities; opportunity to keep pace with global skill and knowledge and career progression 
were found to be factors of academic turnover by Issa \& Adebola (2014) and Ayinde \& Adegoroye (2012). Supervisor and supervisor supports were found to be potent push factor of employees' turnover by Hira (2011), Borstoff\& Marker (2007), Sandhya \& Kumor (2011). Also reported as turnover factors are denial of opportunities (Agba, Ogabor \& Ushie, 2010), and exclusion tendencies (Meyer \& Topintsky 2000). Stimulating, challenging and meaningful work were found by Muatz (2015) and Samuel \& Chipunza (2013) to be some reasons of employee turnover. Studies revealed that reward system and justice are factors pushing employees to other organization. Employees are comfortable with leaders that can be trusted, who treat them fairly and give them sense of recognition and satisfy their need for knowledge acquisition as Borstoff \& Marker (2007) corroborated.

\section{Effect of Effective Retention Strategies on Staff Turnover}

Minimizing employees turnover through effective retention strategies in academic and research landscape is important for the fact that employees that have served an organization for a considerable number of years possess specialized institutional knowledge neededfor competitiveness (Nasir \& Sabiri, 2012), meet business objectives and organizational competence (Hira, 2011), and ensure sustainability and quality over a long period of time (Ng'ethe, et al, 2012).

\section{Cost of Staff Turnover on Organization Outcomes}

Beyond the issue of the benefit of retention, employee turnover is a huge costs to an organization (Nasir \& Sabiri, 2012; Haider, Rasili, Shoaib, Mohammed ibn Yusuff, Maliki, Aamir, Arif, Naheed \&Tariq, 2015; Nelson \&McCann 2012). The loss has been variously categorised and described.The loss of institutional knowledge and employee with specific knowledge (Nasir \&Sabiri, 2012; Samuel \& Chinpuza, 2013; Ng'ethe et al, 2012; Haider, et al, 2015; Nelson \& McCann). Knowledge workers have high degree of education, experience, expertise that drive long term competitive performance when there is an enabling environment where such knowledge can be created distributed, applied and are not taking away to other organizations. Haider, et al, (2015) studies revealed that employee turnover has a burden effect on the remaining employees. Such employees may want to also quit if the push forces are overwhelming

Replacement cost of exited employee is estimated to be eighteen to thirty months of the salary of the individual (Borstoff \& Marker, 2007). Other losses related to employees, turnover are loss of customers, business and damaged morale.Academics turnover leads to disruption in courses offerings, discontinuities in planning for students and faculties, loss of graduates' advisors/supervisors, quality and disruption of strong social and colleagueal relations that motivate to higher performance

\section{Theoretical Framework}

Social exchange theory by Blau (1964) is one of the theories that are used to understand behaviours of individuals on work related issues. Individuals see themselves as involved in exchange relationship with the organization of which they are members. Continued membership of the organization is based on a cognitive evaluation of cost and benefits of remaining in the relationship.

In the context of the study the employees evaluate their organization retention strategies in terms of their deliverables and what they get in return from their employers. If found sufficient and beneficial there is the likelihood of them remaining in the organization and continue to deliver dependably and committedly on their work. If on the other hand they are not so found they quit the organization.

\section{Conceptual Framework}

\section{Fig1: Retention Strategies and Turnover}

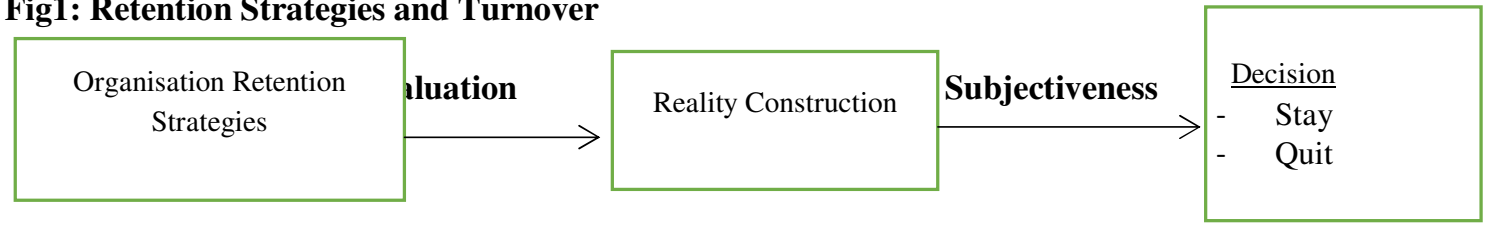

Source: Author (2017) 
The thrust of the framework is that every organization has some retention strategies in place to attract and retain competent and talent workers. The operational effectiveness of these strategies is subjected to evaluative measure by employees to ascertain their sufficiency and adequacy in meeting their expectations and value propositions. A reality is constructed in interaction with other workers to arrive at collective sense making (CSM). Reality is socially constructed about the strategies. Individuals make their subjective decisions on the constructed realities. If constructed reality is satisfactory after considering external offerings (pull factors), the employee decides to stay and be committed to the company. The turnover risk factor of the organization is, in such a situation, low. If on the other hand, the reality is not satisfactory and the pull factor is strong the turnover risk factor is high. The employee will decide to quit the organization to a more satisfactory setting

\section{Research Method}

Exploratory research design was adopted for this study. This is informed by the fact that research is sparse on why academic staff stay or leave their institutions to another.The study is limited to two Lagos State owned tertiary institutions' academic staff - Lagos State University (LASU) and Adeniran Ogunsanya College of Education (AOCOED). It also covers turnover occurrences for ten (10) years: 2005 - 2015 for all categories of academic staff. It does not cover those who retired due to statutory retirement age or are dismissed for disciplinary actions.

The Key Informant Interview (KII) mixed with Focus Group Discussion (FGD) were used to investigate academic staff that had left in the period of ten years spanning the years between 2005 to 2015 . The instruments were informed by the need to have a deep insight into and probe deeper the reasons of leaving (Abanihe-Isiugho, 2002) of academic staff and where they moved to. No document in the institutions Registry provided this information as staff severance interview were not a practice of the two institutions. Further, those who have exited cannot be reached as there were no contact addresses where they can be reached

The respondents include Heads of academic establishment, Deans of Faculty, Heads of Department and academic staff who had spent over ten years continuously in the institutions up till the year 2015. Three (3) academic staff that met these criteria in each department of the institutions were purposively picked as respondents. This is justified by the fact that such selected respondents are in the possession of institutional knowledge, should have interacted with the staff that left and would more likely be aware of the turnover intention of the staff who left and where they moved to.

The key informant interview (KII) was used to investigate the number of academic staff that left each department in the years under investigation and where they left to. It also provided information on the cadres of academic staff that left by their department. It was also used to investigate the retention strategies in place in the institution

The Focus Group Discussion (FGD) probed into, and sought deep insight into the reasons for quitting of each academic staff, leadership, promotion, career advancement and training leave.

The study used descriptive statistics to analyse data collected.

\section{Results and Discussions}

Objective 1: To investigate if retention strategiesput in place by the institutions influence retention.

Table 1: Total Number of Staff That Exited by Turnover Factors

\begin{tabular}{|l|c|c|c|c|}
\hline & \multicolumn{2}{|c|}{ LASU } & \multicolumn{2}{c|}{ AOCOED } \\
\hline LEADERSHIP & 27 & $29 \%$ & 0 & $0 \%$ \\
\hline PROMOTION & 24 & $26 \%$ & 0 & $0 \%$ \\
\hline TRAINING LEAVE & 23 & $24 \%$ & 0 & $0 \%$ \\
\hline CAREER ADVANCEMENT & 8 & $9 \%$ & 11 & $92 \%$ \\
\hline RETIREMENT & 12 & $13 \%$ & 0 & $0 \%$ \\
\hline RELOCATION & 0 & $0 \%$ & 1 & $8 \%$ \\
\hline Total & $\mathbf{9 4}$ & $\mathbf{1 0 0 \%}$ & $\mathbf{1 2}$ & $\mathbf{1 0 0 \%}$ \\
\hline
\end{tabular}

A total number of 82 academic staff members left Lagos State University (LASU) voluntarily between 2005 and 2015, compared to AOCOED 11, while 12 LASU staff left for factor of involuntary (statutory retirement) compared to AOCOED 1 for reason of relocation as table 1 indicated. 
Fig.2a indicates that more professors $18(22 \%)$, left LASU at this periodfollowedin this decreasing order: $17(20.7$ \%)Assistant Lecturer, 16 (19.5 \%) Lecturer 1, 14(17.07 \%) Senior Lecturer, 12(14.6 \%) Lecturer 2 and 4(17.07) Associate Professor. Like in LASU, more of the topmost cadre voluntarily exited in AOCOED. However, the Senior Lecturers are more, unlike Professors in Lasu. 4(33.3\%) senior staff left AOCOED during the period followed in descending order by 3(25\%) Chief lecturer, 2 (16.6\%)Principal Lecturer, $2(16.6 \%)$ Lecturer 1 and $1(8.3 \%)$ Lecturer 111 as shown in Fig. 2b. Whereas, more of professors exited in LASU, the senior lecturers exited more in AOCOED. This does not show the same pattern.

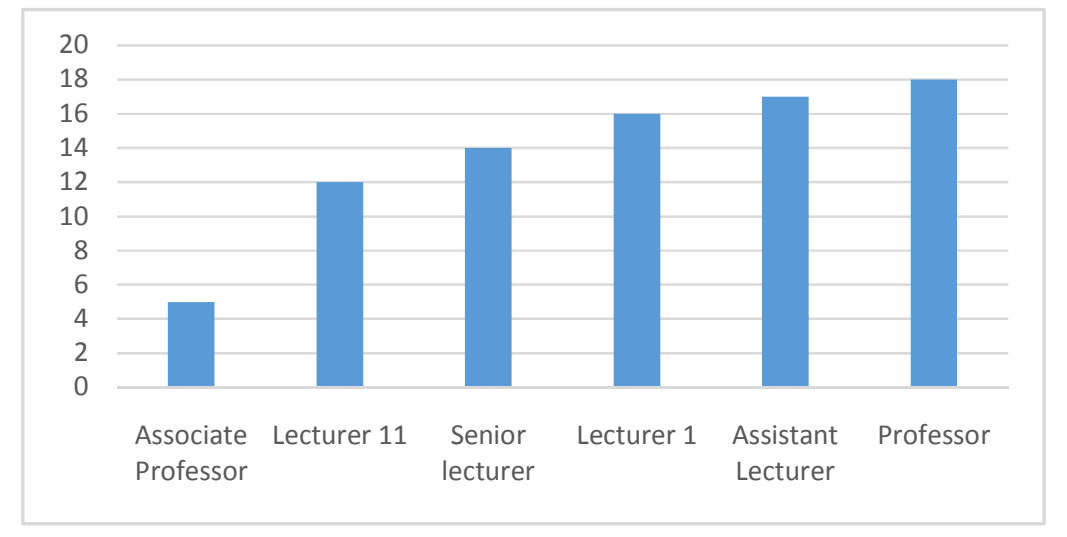

Fig. 2a: Total Number of Turnover by Staff Cadre (LASU)

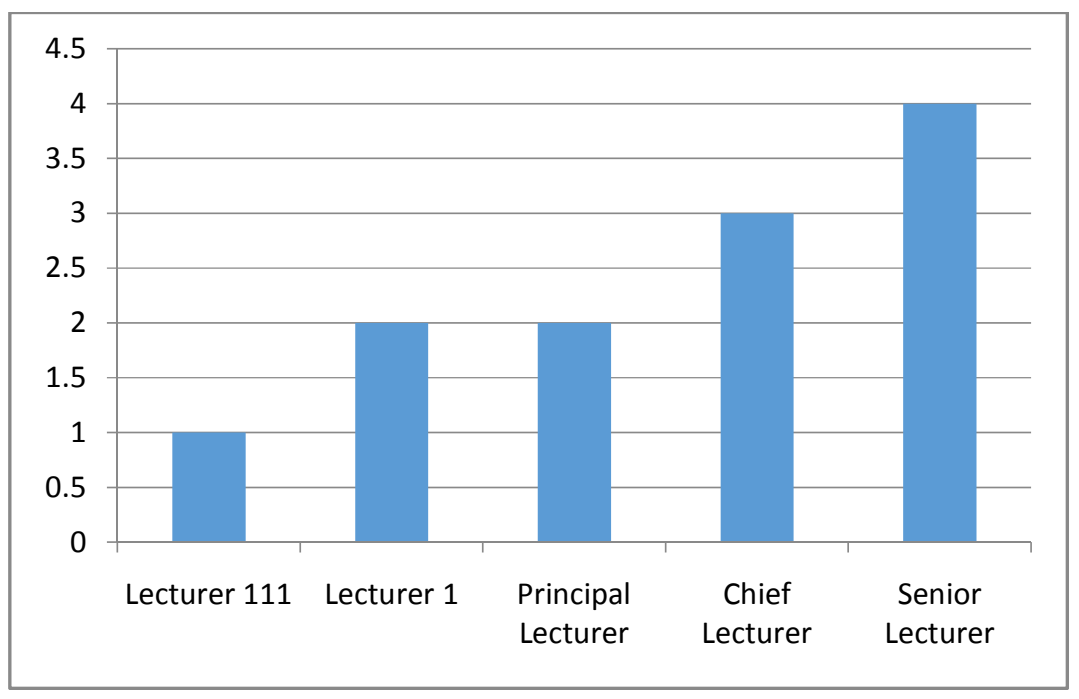

Fig 2b: Total Number of Turnover by Staff Cadre (AOCOED)

Table 2: Voluntary Exit

\begin{tabular}{|l|c|c|c|c|}
\hline & \multicolumn{2}{|c|}{ LASU } & \multicolumn{2}{c|}{ AOCOED } \\
\hline LEADERSHIP & 27 & $33 \%$ & 0 & $0 \%$ \\
\hline PROMOTION & 24 & $29 \%$ & 0 & $0 \%$ \\
\hline TRAINING LEAVE & 23 & $28 \%$ & 0 & $0 \%$ \\
\hline CAREER ADVANCEMENT & 8 & $10 \%$ & 11 & $100 \%$ \\
\hline Total & $\mathbf{8 2}$ & $\mathbf{1 0 0 \%}$ & $\mathbf{1 1}$ & $\mathbf{1 0 0 \%}$ \\
\hline
\end{tabular}




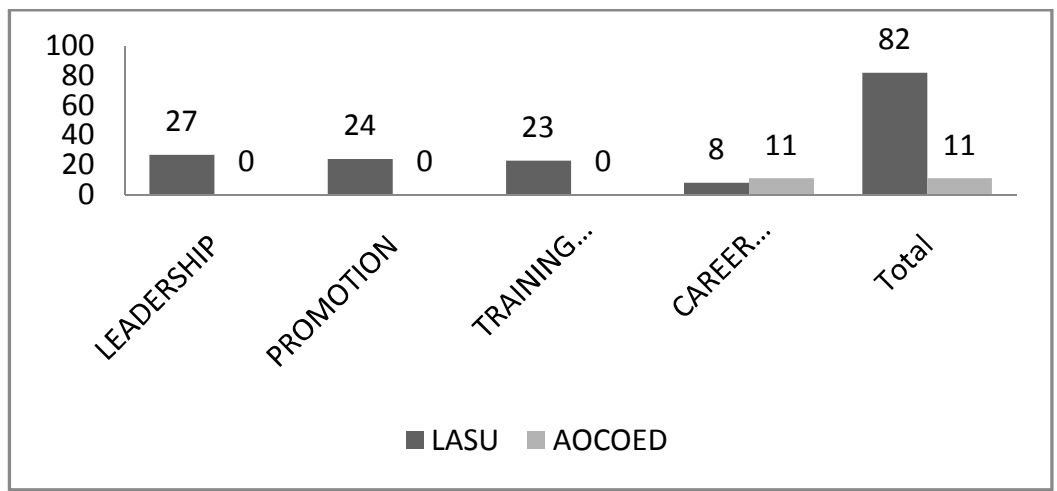

Fig 3: Comparison of Push factors of staff exit

Table 2 shows the voluntary exit based on retention strategies; Leadership, promotion and training leave were reported at LASU as reasons for quitting. Only career advancement was reported from the two institutions. This suggests that leadership, promotion and training leave as retention strategies could be defective in LASU and not in AOCOED as at the period under study. Table 2 and fig 3 show that 27 (33\%), 24(29\%), 23 (28\%) left LASU for reasons of leadership style, promotion, training leave and none left in AOCOED for the same reasons. There was however similar pattern for career advancement in the two institutions: $8(10 \%)$ and $11(100 \%)$ in LASU and AOCOED respectively. These are those that move to other institutions to take up higher appointments like professors for Chief Lecturer of AOCOED, or responded to higher position offer in other institutions for LASU academic staff.

\section{Table 3 Issues in the Reasons for Quitting}

\begin{tabular}{ll}
\hline Reasons for quitting & Issues in factor of quitting \\
\hline Leadership & $\begin{array}{l}\text { High-handedness, witch-hunting, creating unconducive work } \\
\text { environment, promotion of climate of silence, divisive tendencies } \\
\text { Selective promotion. Change in promotion policies. denial of } \\
\text { promotion }\end{array}$ \\
Paking higher positions elsewhere, perception of lack of prospect \\
Career Advancement & $\begin{array}{l}\text { Inadequate funding, stoppage of salary when on training, stoppage } \\
\text { of institution support while on training, Lack of bosses support }\end{array}$ \\
Training leave &
\end{tabular}

Table 3 revealed the issues in the factor of quitting as revealed by the focus group discussion

\section{Objective 2}

To investigate if quitting risk factors are different among different categories of academic staff.

Table: 4 Factors of quitting by Cadre (LASU)

\begin{tabular}{|c|c|c|c|c|c|c|c|}
\hline & $\begin{array}{l}\text { Profe } \\
\text { ssor }\end{array}$ & $\begin{array}{l}\text { Associate } \\
\text { Professor }\end{array}$ & $\begin{array}{c}\text { Senior } \\
\text { Lecturer }\end{array}$ & Lecturer 1 & $\begin{array}{c}\text { Lecturer } \\
11\end{array}$ & $\begin{array}{l}\text { Assistant } \\
\text { Lecturer }\end{array}$ & Total \\
\hline LEADERSHIP & 18 & 3 & 4 & 2 & 0 & 0 & 27 \\
\hline $\begin{array}{l}\text { CAREER } \\
\text { ADVANCEMENT }\end{array}$ & 0 & 2 & 0 & 6 & 0 & 0 & 8 \\
\hline PROMOTION & 0 & 0 & 10 & 0 & 6 & 8 & 24 \\
\hline TRAINING LEAVE & 0 & 0 & 0 & 8 & 6 & 9 & 23 \\
\hline TOTAL & 18 & 5 & 14 & 16 & 12 & 17 & 82 \\
\hline
\end{tabular}

It is observed from table 5 above that quitting risk factors are actually different among different categories of academic staff of LASU. This is in contrast to AOCOED where career advancement accounted for exit of all levels of academic staff in that institution (Table 6). Academic staff quitted, to take up new career in universities so as to rise to professorial cadre that does not exist in Colleges of Education.

All the Professors 18(100\%) left the system because of reasons associated with leadership/management style. This shows the importance of management/ leadership effectiveness to retain professorial cadre as 3(60\%) Associate Professors left for the same reason of leadership style. Opportunities for development and growth were found 
among academic staff of Lecturer 1 down to assistant lecturer to be the reasons for quitting. In conclusion, the study found out that majority (36\%) of those who left LASU did so owing to leadership position followed by reasons associated with promotion (32\%). 15 (20\%) left with the aim of getting trained elsewhere and 8 left for reason of career advancement in other institutions

Table 5: Reasons for Quitting by cadre (AOCOED)

\begin{tabular}{|c|c|c|c|c|c|c|}
\hline & $\begin{array}{l}\text { Chief } \\
\text { Lecturer }\end{array}$ & $\begin{array}{l}\text { Principal } \\
\text { Lecturer }\end{array}$ & $\begin{array}{l}\text { Senior } \\
\text { Lecturer }\end{array}$ & Lecturer 1 & $\begin{array}{l}\text { Lecturer } \\
111\end{array}$ & Total \\
\hline $\begin{array}{l}\text { Career } \\
\text { Advancement }\end{array}$ & 3 & 1 & 4 & 2 & 1 & 11 \\
\hline
\end{tabular}

The study observed that retention strategy factors in the institutions are relative in nature. The management/leadership style, organizational culture, organizational climate (environment), inherent in the institution to a very large extent, determine the reasons of staff turnover.

The reasons why academic staff left an institution (push) is the same reasons that attracted them to other institutions. Quitting risk factors are different among different categories of academic staff, and certain retention strategy factors are more impactful risk factors than others in leading to quitting in the University and the College.

\section{Summary of Findings}

Tertiary institution has its peculiarity in value propositions or expectations from the management that attract and retain employees. More importantly, leadership was found to be key in academic staff turnover. Leadership captures issues of management supportiveness, creating conducive environment and climate that is satisfactory to majority of staff. It also includes empowerment, justice and uniformity of treatment of staff. Leadership was responsible for the voluntary turnover of all the professors that left LASU. This suggests that academic staff on this cadre require autonomy and independence, involvement, assertiveness and self-actualization. These suffer frustration of actualization in LASU accounting for the high turnover rate of academic staff on professorial cadre and less in others. This is in line with the findings of N'gethe, et al (2012) for South Africa Training Institutes that leadership that includes top management and chairmen of department play crucial roles in portraying to the staff that their university is the employer of choice. Even if employment exist elsewhere an effective leadership strategy will make them stay and be committed to the institution, otherwise they quit. It is also in alignment with corporate pride and trust in the chief executive as found by Samuel and Chinpuza (2012) as the topmost retention strategy or factor of attrition in South Africa's universities. and exclusion tendencies as found by Meyer \& Topintsky (2000).The situation was different in AOCOED where these needs seem to be met and no turnover on the basis of leadership. Leadership affects other turnover factors of the institutions. Training and development, career advancement, culture and climate are the creation of the management. That could be the reasons for the distinguishing factor between LASU and AOCOED. Management support for other retention factors accounted for the quitting in AOCOED to be only reason of turnoverCareer advancement, training and development were important retention strategies in retaining academic staff on Assistant Lecturer to Lecturer 1. Access to training and development programs are found as essential needs of these groups of academic staff. Frustration of these needs accounted for the turnover recorded for the groups. This confirms the findings of Hira (2011) that career development and opportunities for growth are imperative for both individual and organizational context for retention and turnover. It is alsoin line with the opportunity to keep pace with global skill and knowledge and career progression as found to be factors of academic turnover by Issa \& Adebola (2014) and Ayinde \& Adegoroye (2012). Denial of training opportunities and consequent turnover by academic staff in need of such is also confirmed by the work of Agba, Ogabor and Ushie (2010).

\section{Conclusion and Recommendations}

The studyexplored the factor of turnoverpeculiar to academic staff in two Lagos State owned institutions. The identified peculiar retention strategies (leadership, promotion, training and career advancement) to tertiary institutions were risk factors to organization. Their effectiveness, in operation, serves as a pull factor in attracting and retention of staff. They are risk push factors to organization as their frustration in expectation led to turnover of academic staff. Management/leadership styles, opportunities for training, growth and development, career advancement and promotion were identified as the flash factor of turnover peculiar to tertiary institutions' academic staff. 
Management and leadership disposition towards all categories of academic staff stands out as pull factor of retention or serves as push factor of turnover. This account for the differences observed between Lagos State University and AdeniranOgunsanya College of Education. The leadership style evaluation by academic staff of AOCOED seems to meet expectations, psychological contract value proposition of the staff; and therefore does not account for turnover in the institution. This is not so in LASU. The study finds the rate of turnover in LASU as high especially among the professorial cadre. Leadership issue accounted for the entire voluntary turnover among professors in the universities, Career advancement and opportunities for growth were important for retention and turnover in academic institutions for other cadres of academic staff. The rate at which staff on professorial cadre was lost constituted huge cost to LASUwhich include institutional knowledge neededfor competitiveness (Nasir \& Sabiri, 2012), the need to meet business objectives and organizational competence (Hira, 2011), and ensuring sustainability and quality over a long period of time (Ng'ethe, et al, 2012).

\section{Recommendations}

Based on the peculiarity of retention and turnover factors of tertiary institutions, the following are recommended: Leadership which includes the management, head of faculties and heads of department and of units need to periodically survey the value placed on their institutions retention strategies in terms of adequacy, sufficiency, fairness and equity in their implementation.

It is imperative to build the trust of staff towards the management in terms of policies enacted and guide against same policies being applied differently to staff in similar circumstances. Standard should be in line with the global practice in the industry and there should be elimination of double standard. Trust also demands that lip service to opportunities accruing to staff from the management should be eradicated. External opportunities that serve as turnover factors (pull factors) should be given adequate consideration in formulating retention strategies so as not to further lose academic staff.

Management styles need to be democratic, devoid of hunting down. It should guarantee autonomy if academic staff would not migrate to other institutions where such culture would be enjoyed. Academic staff on senior lecturer and professorial cadres, require more of autonomy and independence, involvement, assertiveness and self-actualization. Otherwise they move to other climes that enable such offerings.

\section{Refrences}

Abanihe-Isiugho, U.C. (2002). Quantitative research technique In Abanihe-Isiugho, Isamah, A.N \& Adesina, J.O. (Eds.). Currents and perspectives in sociology. Lagos: Malthouse

Agba, A.M., Ogabor, \&Ushie, E.M. (2010). Motivational incentives and staff turnover in Nigeria hospitality industry in Cross River State. Nigeria. Global Journal of Management and Business Research. 10(8),1828

Ajadi, T.M.(2010).Private universities in Nigeria- the challenges ahead. American Journal of Scientific Research issue, 7,15-24.

Akindele, R. I. ,Oginni, B. O. \&Omoyele, S. O. (2012). Survival of private universities in Nigeria: issues, challenges and prospects.International Journal of Innovative Research in Management, 1(2), 30- 42.

Awan, W.A. (2013). Impact of employee orientation on retention: A case of service sector organizations in Pakistan. Interdisciplinary Journal of Contemporary Research in Business, 5(4), 326-332.

Ayinde, A.T \&Adegoroye, A.A.(2012). Employees' perception of career progressionand turnover intentionamong bank workers in the Central Local Government Area, Osun State.Research Journal in organizational psychology and Educational studies, 1(6) 353-360.

Bhatt, B. (2015). A study of organization culture in relation to employee retention. International Journal Of Science and Technology Management, 4(03).

Borstoff, P C.\& Marker, M. B. (2007). Turnover drivers and retention factors affecting hourly workers: What is Important. Management Review, 2(1), $14-29$.

Chukwu, O.S., Ofotokun, J.T, Fadeji, \&Sule, V.U. (2013). The causes of labour turnover in bottling companies in Nigeria: a comparative study of Coca cola and Seven Up plc. Lagos, Nigeria. Asian Journal of Business Management, 5 (4), 339-347.

Gberevbie, D. (2009). Personnel recruitment and retention Strategies in Lagos civil service of Nigeria. African Research Review of Business \& Management, 3(3), 226-243.

Gberevbie, D. (2010). Strategies for employee recruitment, retention and performance: Dimension of the Federal Civil Service of Nigeria. African Journal of Business Management, 4(8), 1447 - 1456. 
Haider, M., Rasli, A., Shoaib, C., Mohammed Yousuff, A.R., Malik, O.M., Amir, A., Arif, A., Nareed, S. \& Tariq, F. (2015). The impact of human resource practices on employee retention in telecom sector. International Journal of Economics and Financial, issue 5(Special Issue), 63-69.

Hira, F, (2011). Does employee retention affects organizational competence.Industrial Engineering Letters, 1 (1) $24-35$.

Ibrahim, A. M., Usman, B. U. \& Bagudu, M. W. ( 2014). Employee Turnover and its effects on organizational productivity of State owned institutions in Niger State.

Irshad, M. (20). Factors affecting employee retention.Abasyn Journal of Social Science, 4(1), 84-102.

Issa, A. \& Adebola, D. E. (2014). The implication of employees' turnover in Nigeria Higher Education. Journal of Research Development, 1(10), 44-52.

Meyer, J. \& Toplntsky, L. (2000). Organization culture and practice in Meyer, J.\&Toplntsky(2000). Best practices: Employee retention.

Mohanty, S. \& Mohanty, K. (2014). Employee retention: A key driver to the growth of tourism and hospitality in Odisha. International Journal for Innovation Education and Research, 3(13), 94-112.

Nasir, S. \& Sabir, H.M. (2012). The effect of organization culture and climate on employees' retention in Pakistan. Elixir Human Resource Management, 4(2), 6097-6105.

Nelson, K. \&McCann, J.E. (2012) Designing for knowledge workers retention and performance. Journal of Management and marketing Research, 1, 1-18.

Ng'ethe, J. M. Iravo, M. \& Namusonge, G.S. (2012). Determinants of academic staff retention in public universities in Kenya: Empirical reviews. International Journal of Humanities and Social Science,2(13) $205-212$.

Oginni, R.O.Ogunlusi, C.F. \& Faseyiku, I.O. (2013). A study of employees; retention strategies and organization survival in private universities in south-west Nigeria. The International Journal of Management, 2(1), 117.

Samuel, M. O. \& Chipunza, C. (2013). Attrition and retention of senior academics at institution of higher learning in South Africa: The strategies complexities and realities. Journal of Social sciences, 35(2), 97 - 109.

Sandhya, K. \& Kumor, P.(2011). Employee retention by motivation. Indian Journal of Science and technology,4(12),1778-1782.

Scheneider, B \& Reichers, A.E. (1993). On the etiology of climate. Personal Psychology, 36, 19-39.

Sharidon, J.E. (1992).Organization culture and employee retention. The Academy of Management Journal, 35(5), 1036-1056.

Vasquez, D. (2014).Employee retention for economic stabilization: A qualitative phenomenological studying the hospitality sector. International Journal of management economics and Social Sciences, 3(1), 1-17. 